\title{
Review of hysterectomies in Department of Obstetrics and Gynaecology at tertiary care hospital in Northern India
}

\author{
Vandana Solanki*, Urmila Singh, Seema Mehrotra, Shuchi Agarwal, Apala Priyadarshini
}

Department of Obstetrics and Gynecology, King George's Medical University, Lucknow, Uttar Pradesh, India

Received: 24 September 2018

Accepted: 01 November 2018

* Correspondence:

Dr. Vandana Solanki,

E-mail: solanki.vandana@gmail.com

Copyright: (C) the author(s), publisher and licensee Medip Academy. This is an open-access article distributed under the terms of the Creative Commons Attribution Non-Commercial License, which permits unrestricted non-commercial use, distribution, and reproduction in any medium, provided the original work is properly cited.

\begin{abstract}
Background: With the advancement of newer and conservative approach in the management of many gynaecological conditions, hysterectomy still remains the chief modality of treatment. The aim of this study was to analyze the various indications, clinical profile, and outcome of all the patients who underwent hysterectomy at premier teaching hospital in Northern India.

Methods: This study involved all the patients who underwent hysterectomy from 1st Jan 2017 to 31 st Dec 2017 in tertiary care hospital India.

Results: Out of total 513 hysterectomies, 105 were obstetric and 408 were gynaecological hysterectomies. In obstetric hysterectomies $40 \%$ were due to rupture uterus, $38 \%$ were due to abnormal placentation. In gynaecological hysterectomies, $75.5 \%$ abdominal \& $24.5 \%$ were vaginal.75.7 \% were for benign conditions and $24.3 \%$ were for malignant conditions. Most common indication was AUB.

Conclusions: Hysterectomy is commonly done to improve the quality of life but at the same time in obstetrics emergencies it's a lifesaving procedure. So, its indications should be clearly evaluated, and patient should be clearly counselled about conservative options, risk and benefits of the procedure.
\end{abstract}

Keywords: Hysterectomy, Obstetric, Vaginal

\section{INTRODUCTION}

Hysterectomy is the second most common operative procedure performed on women in world after lower segment caesarean section. Its incidence varies between 6.1 to 8.6 per 1000 women of all ages. ${ }^{1}$ Most common indications are AUB associated with fibroid, endometriosis, adenomyosis and uterovaginal prolapse. ${ }^{2}$ But in Obstetrics it becomes a lifesaving procedure when all other methods fail to control post-partum haemorrhage. All the large-scale surveys of hysterectomy practice have shown that most of the hysterectomies are performed by abdominal route. ${ }^{3}$ It can be done vaginally and laparoscopically also. Route depends upon indication, surgeon's preference and nature of disease. As with all other major surgical procedures it is not free of complications. There may be intra or post-operative complications. Rates of various complications vary from $0.05 \%$ to $43 \% .{ }^{4}$ With the advent of newer modalities of conservative management in various uterine pathologies, indications of hysterectomy should be clear-cut. It is also observed that ovarian functions also decline rapidly after removal of uterus.

Mean age of menopause in women who underwent hysterectomy is 3.7 years earlier even if we preserve ovaries. ${ }^{5}$ The aim of this audit was to evaluate the various indications, route and histopathologic association of all hysterectomies performed at tertiary care teaching hospital in Northern India. 


\section{METHODS}

This study involved all women who underwent hysterectomy at Department of Obstetrics and Gynaecology King George's Medical University Lucknow. This was a retrospective cohort study and included all cases of hysterectomy from 1st Jan 2017 to 31st Dec 2017. Records from register and case sheets of patients were collected.

There were no exclusion criteria. Patients were identified by medical record tracking. Data collected regarding age, parity socioeconomic status, clinical profile, chief complaints, major medical history, any previous operative history, indications, routes of hysterectomy, duration of hospital stay.

Baseline investigations including $\mathrm{CBC}$, Blood sugar, urine complete examination, ECG, $\mathrm{X}$ ray chest, USG, viral markers were noted.

Data collected for post-operative complications, transfusions, histopathology was collected. Haemoglobin level was build up and blood transfusions were done according to haemoglobin level. All the hysterectomies were included elective as well as emergency.

Abdominal hysterectomies included supracervical, TAH, TAH with unilateral salpigoophrectomy, TAH with BSO, as part of staging laparotomy as a part of ovarian malignancy and also included wertheim's hystrectomy. Vaginal hysterectomies included the VH with PFR for prolapse and non-descent vaginal hyatrectomy (NDVH) for other indications. After collecting data various indications were reviewed. Special emphasis was given on indication of hysterectomy $<30$ years of age. Maximum patients were discharged between 7 th and 10th post-operative day. The data was analyzed using percentages.

\section{RESULTS}

A total of hysterectomies 513 were performed in the study period. Out of these $105(20.5 \%)$ were obstetrical and $408(79.5 \%)$ were gynaecological. Out of 408 gynaecological $308(75.5 \%)$ were abdominal and $100(24.5 \%)$. Table 1 is showing age wise distribution of subjects who had Obstetrical hysterectomy.

Table 1: Distribution of obstetric hysterectomy according to age.

\begin{tabular}{|lll|}
\hline Age & No. & $\%$ \\
\hline $20-25$ & 16 & 15.2 \\
\hline $26-30$ & 55 & 52.4 \\
\hline $31-35$ & 21 & 20 \\
\hline $36-40$ & 13 & 12.4 \\
\hline
\end{tabular}

Table 2 is showing distribution of subjects of obstetric hysterectomy according to parity.
Table 2: Distribution of obstetric hystrectomy according to parity.

\begin{tabular}{|lll|}
\hline Parity & No. $(\mathbf{n = 9 5})$ & $\%$ \\
\hline P1 & 1 & 0.9 \\
\hline P2 & 31 & 29.6 \\
\hline P3 & 35 & 33.3 \\
\hline P4 & 26 & 24.8 \\
\hline P5 and above & 12 & 11.4 \\
\hline
\end{tabular}

Maximum 55 (52.4\%) subjects were between age 26-30 years. Table 3 is showing distribution of subjects according to indication of obstetrical hysterectomy. Rupture uterus (40\%) was most common followed by abnormal placentaion (38.1\%).

Table 3: Distribution of subjects according to indication for obstetric hysterectomy.

\begin{tabular}{|llc|}
\hline Indication & No. (105) & $\%$ \\
\hline Uterine atony & 16 & 15.2 \\
\hline Abnormal placentation & 40 & 38.1 \\
\hline Placenta accrete & 28 & \\
\hline Placenta percreta & 12 & \\
\hline Rupture uterus & 42 & 40.0 \\
\hline Post-partum uterine infection & 4 & 3.8 \\
\hline Post D and C perforation & 3 & 2.9 \\
\hline
\end{tabular}

Maximum subjects 177 (43.6) had age group 51-60 years followed by $31-40$ years. $308(75.6 \%)$ had abdominal hysterectomy and 100 (24.5\%) underwent vaginal hysterectomy (Table 4).

Table 4: Distribution of gynaecological hysterectomy according to age.

\begin{tabular}{|lll|}
\hline Age (Years) & No. (408) & $\%$ \\
\hline$<30$ & 15 & 3.6 \\
\hline $31-40$ & 104 & 25.5 \\
\hline $41-50$ & 177 & 43.6 \\
\hline $51-60$ & 77 & 18.0 \\
\hline $61-70$ & 29 & 7.2 \\
\hline$>70$ & 6 & 1.4 \\
\hline
\end{tabular}

$309(75.7 \%)$ had benign indication of hysterectomy and $99(24.3 \%)$ had malignant (Figure 1).

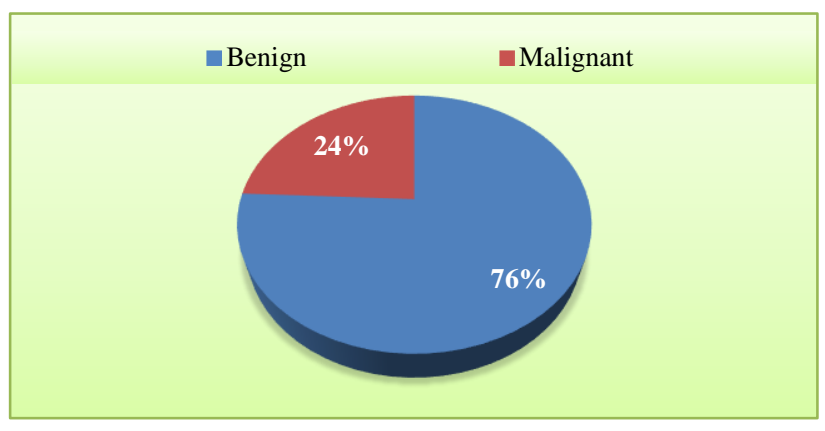

Figure 1. Distribution of subjects according to nature 
Table 5 is showing distribution of subjects of gynaecologic hysterectomies according to indication. 149 $(36.5 \%)$ underwent hysterectomy as a consequence of AUB, and among them the most common was leiomyoma $81(19.9 \%)$ followed by adenomyosis 35 $(8.5 \%)$.

Apart from AUB, 48 (11.8\%) patients had hysterectomy because of fibroid uterus. Approximately one third of the patients had vaginal hysterectomy.

Table 5: Distribution of subjects according to indications (benign).

\begin{tabular}{|lll|}
\hline Indication & No. & Percentage \\
\hline AUB & 149 & 36.5 \\
\hline AUB-P & 16 & 3.9 \\
\hline AUB-A & 35 & 8.5 \\
\hline AUB-L & 81 & 19.9 \\
\hline AUB-N & 17 & 4.2 \\
\hline Uterine prolapse & 100 & 24.5 \\
\hline Fibroid uterus & 48 & 11.8 \\
\hline Endometriosis & 5 & 1.2 \\
\hline Benign ovarian neoplasm & 7 & 1.7 \\
\hline
\end{tabular}

Table 6 is showing distribution of subjects according to indication of hysterectomy in malignant group. Most common indication for hysterectomy was carcinoma ovary $41(10 \%)$ followed by carcinoma cervix $24(5.9 \%)$.

Table 6: Distribution of subjects according to indications (malignant).

\begin{tabular}{|lll|}
\hline \multicolumn{1}{|c}{ Indication } & No. & $\%$ \\
\hline Carcinoma ovary & 41 & 10.0 \\
\hline Carcinoma cervix & 24 & 5.9 \\
\hline Carcinoma endometrium & 23 & 5.6 \\
\hline Benign atypical hyperplasia & 5 & 1.2 \\
\hline CIN III & 5 & 1.4 \\
\hline GTN & 1 & 0.2 \\
\hline
\end{tabular}

Among nulliparous women 20 women had abdominal hysterectomy and the indications were carcinoma ovary $5(25 \%)$ followed by fibroid uterus $4(20 \%)$. Table 7 is showing indication of hysterectomy in women $<30$ years. Leiomyoma (AUB-L) was the most common 5 (33.3\%) followed by carcinoma ovary $4(26.6 \%)$. One woman underwent hysterectomy as a consequence of cervical agenesis.

Table 7: Indications of hysterectomy in <30years age.

\begin{tabular}{|lll|}
\hline Indication & No. $(\mathbf{n}=15)$ & $\%$ \\
\hline AUB-L & 5 & 33.3 \\
\hline Carcinoma Ovary & 4 & 26.6 \\
\hline Carcinoma cervix & 2 & 13.2 \\
\hline Carcinoma endometrium & 1 & 7 \\
\hline Fibroid uterus & 2 & 13.2 \\
\hline Cervical agenesis & 1 & 7 \\
\hline
\end{tabular}

\section{DISCUSSION}

In the year 2017 in our busy tertiary care hospital, a total of 91,595 women attended our outpatient department (OPD). 19229 were admitted in the hospital. Out of which 6738 patients were treated with some major surgical procedure which included 513 hysterectomies. Hysterectomy is the most common non-pregnancy procedure performed on women. ${ }^{6}$ There are various indications of hysterectomy but when it comes to obstetrics it becomes a lifesaving procedure. In our hospital 105 Obstetric hysterectomies were done in a span of 1 year. Most common 55(52.4\%) age group was 26-30 years. 35(33.3\%) were P3, 31(29.6\%) were P2 and one patient $(0.9 \%)$ was $\mathrm{P} 1$.

Most common indication was rupture uterus $42(40 \%)$ followed by abnormal placentation 40(38.1\%). 89(84.2\%) patients were referred to our hospital as it's a tertiary care hospital. Placenta accrete and percreta led to obstetric hysterectomy in $40(38.1 \%)$ patients because of uncontrolled haemorrhage. So, in primi patient indication of lower segment caesarean section should be very clear and justified to avoid further LSCS and development of placenta accrete and percreta. We should sensitize the general population regarding the long-term complications of CDMR (Caesarean Delivery on Maternal Request) to reduce the number of LSCS.

Obstetric haemorrhage continues to be the most important cause of maternal mortality in India. ${ }^{7}$ Our primary focus should be on reducing maternal mortality rather than preventing morbidity. "Maternal near miss" surveillance is an effective tool for improving safe motherhood programs. ${ }^{8}$ In our case, morbidly adherent placenta was the second most common indication for EOH (Emergency Obstetric Hysterectomy). This was also the case in Turkey and the UK contributing to $40 \%$ and $38 \%$ of cases, respectively. Korejo et al from Pakistan recently reported that $47.1 \%$ of cases were the result of uterine rupture, $28.9 \%$ from atony, and $17.4 \%$ from placental causes. ${ }^{9,10}$ Of all the cases of uterine rupture, $74 \%$ had an unscarred uterus. ${ }^{11}$ Maximum patients $177(43.4 \%)$ in present study belong to age group 41-50 years. Average age at the time of hysterectomy has been increased in India as one study from Gujrat in 2010 showed that $33 \%$ of hysterectomies were performed in women less than 35 years of age. ${ }^{12}$

In our institution in duration of one year we performed 408 gynaecological hysterectomies. Most of these were abdominal $(75.5 \%)$ followed by vaginal $(24.5 \%)$. Almost same observations came from Canada (abdominal 78\%, vaginal 14\%, and laparoscopic 5.9\%). ${ }^{13}$ In Hong Kong the proportion of laparoscopic seemed a little higher (abdominal $70.2 \%$, vaginal $15.9 \%$, and laparoscopic $13.8 \%) .{ }^{14}$ In present study AUB $(36.5 \%)$ was the most common indication for abdominal hysterectomy, among them AUB-L was most common. Fibroid uterus overall lead to hysterectomy in $129(31.7 \%)$ patients. A Nigerian 
tertiary hospital retrospective study showed that uterine fibroid was the leading indication in $38.7 \%$ of patients. ${ }^{15}$ In an Indian study, fibroid uterus $(27.9 \%)$ was the most common indication for hysterectomy, followed by AUB and uterovaginal prolapse. ${ }^{16}$

Out 408, $99(24.3 \%)$ were done due to various genital tract malignancies. $41(10 \%)$ were done due to carcinoma ovary followed by carcinoma cervix 24 (5.9\%) and carcinoma endometrium 23 (5.6\%). Our results are consistent with study done by Pranita et al. They did histopathological audit of 150 patients and found Ovarian tumors were observed in $11.3 \%$ of the hysterectomy cases. $^{17}$

\section{CONCLUSION}

Obstetric hysterectomy is still life saving tool when all medical and other surgical methods fail, although child bearing capacity of women is cut down. Training of our post graduates in this life saving surgery should become integral part of their training. In the ideal conditions we should give all medical management option to patient and after proper counselling hysterectomy should remain last resort. As very few studies are available in India regarding indications, selection of patients, complications of surgery. So regular clinical audit should be done for Gynaecological practice. To further improve the situation, we should be able to provide more medical methods to avoid surgical intervention. These types of audit should be conducted regularly, and this may a basis for further audits.

Funding: No funding sources

Conflict of interest: None declared

Ethical approval: The study was approved by the Institutional Ethics Committee

\section{REFERENCES}

1. AL Kadri HM, AL Burki HA, Saleh A. Short and Long term complications of Abdominal and Vaginal Hysterectomy for disease. Saudi Med J. 2002; 23(7):906-15.

2. Flory N, Bissonette F, Binik YM. Psychosocial effects of hysterectomy: Literature and review. J Psycho Res.2005;59(3):17-29.

3. Begum J, Taludker SIM Hossain MA. A two years audit of complications of Total Abdominal hysterectomy at Dinajpur Medical College Hospital. Dinajpur Med Col J. 2008;1(1):14-17.

4. Lee N, Dicker R, Rubin G, Ory H, Confirmation of the preoperative diagnosis of hysterectomy, Am J Obstet Gynaecol. 1984;150(3);283-287.

5. Farquhar CM, Sadler L, Harvey SA, Stewart AW, The association of hysterectomy and menopause: A prospective cohort study, Int J Obstet Gynaecol. 2005;112(7):956-62.

6. Falcone T, Walters MM. Hysterectomy for benign disease. Obstet Gynaecol 2008;111(3):753-67.

7. Operational guidelines and reference manual prevention of postpartum haemorrhage through community-based distribution of misoprostol. Maternal Health Division Ministry of Health and Family Welfare, Government of India.2013:1-26.

8. Maternal near miss review, Operational Guidelines, December, 2014. Maternal Health Division. Ministry of Health and Family Welfare, GOI.

9. Tapisiz OL, Altinbas SK, Yirci B, Cenksoy P, Kaya AE, Dede S, Kandemir O, Emergency Peripartum hysterectomy in a tertiary hospital in Ankara, Turkey: a 5 year review, Arch Gynecol Obstet. 2012;286(5):1131-4.

10. Knight M, UKOSS. Peripartum hysterectomy in the UK: management and outcomes of the associated haemorrhage. BJOG. 2007;114(11):1380-7.

11. Korejo R, Nasir A, Yasmin H, Bhutta S. Emergency obstetric hysterectomy. J Pak Med Assoc. 2012. ;62(12):1322-5.

12. Desai S, Sinha T, Mahal A. Prevalence of hysterectomy among rural and urban women with and without health insurance in Gujarat, India. Reprod Health Matters. 2011;19(37):42-51.

13. Toma A, Hopman WM, Gorwill RH. Hysterectomy at a Canadian tertiary care facility: results of a one year retrospective review. BMC Women's Health.2004;4:10.

14. Leung PL, Tsang SW, Yuen PM. An audit on hysterectomy for benign diseases in public hospitals in Hong Kong. Hong Kong Med J. 2007;13(3):187.

15. Onyecherellem Ogelle, Charles Okafor, Ahizechukwu C. Eke, Nworah Obiechina, Sunday Mbamara. J Gynecol Surg. 2010; 26(1):7-13

16. Bansal N, Hiremath PB, C Meenal, Prasad V. An audit of indications and complications associated with elective hysterectomy at SVMCH and RC, Ariyur, Pondicherry. Int $\mathrm{J}$ Med Res Health Sci.2013;2(2):147-55.

17. Medhi P, Dowerah S, Borgohain D. A Histopathological Audit of Hysterectomy: Experience at a Tertiary Care Teaching Hospital. Int J Contemp Med Res. 2016;3(4):1226-8.

Cite this article as: Solanki V, Singh U, Mehrotra S, Agarwal S, Priyadarshini A. Review of hysterectomies in Department of Obstetrics and Gynaecology at tertiary care hospital in Northern India. Int J Reprod Contracept Obstet Gynecol 2018;7:4977-80. 